\title{
The role of curriculum theory in contemporary higher education research and practice
} Jyri Lindén, Johanna Annala, and Kelly Coate

Lindén, J., Annala, J. \& Coate, K. (2017) The Role of Curriculum Theory in Contemporary Higher Education Research and Practice, in J. Huisman \& M. Tight (eds.) Theory and Method in Higher Education Research. Volume 3. Emerald, 137-154.

http://www.emeraldinsight.com/doi/full/10.1108/S2056-375220170000003008

\begin{abstract}
In the light of recent debates on the possible issues in curriculum studies, formulated particularly in the field of sociology of education, this paper discusses the role and the importance of curriculum theories in higher education. Focusing on the historical and the conceptual roots of curriculum theory approaches, the argument is that the dispute and the separation between normative and critical roles of curriculum theories are important to overcome in today's competency-based and outcome-focused context of higher education. Basil Bernstein's ideas on the vital role of knowledge are discussed in relation to the origins of the so-called crisis in curriculum theories. It is suggested that in the debate between normative and critical curriculum approaches, a danger is that the focus on the educational importance of curricula may be neglected and silenced in the midst of the pressure to renew curricula in higher education.
\end{abstract}

\section{Introduction}

As a field of study, higher education (HE) research shares much in common with the broader domain of education studies. However, one of the most notable differences is the extent to which curriculum research at the level of compulsory education has become a subfield in its own right, with high-profile theorists and specialised journals dedicated to the subject. Although curricula are commonly investigated in HE research, the field seems to lack a coherent theoretical approach to explaining the meaning and the importance of curriculum, particularly as part of the special role played by HE in society (Annala, Lindén, \& Mäkinen, 2016; Clegg, 2011; Coate, 2009; Fraser \& Bosanquet, 2006). By tracing the historical roots of what we call the divide between normative and critical curriculum traditions (see Young, 2014), our aim in this chapter is to examine and understand the role and the meaning of curriculum theories, specifically in the HE context.

We draw on some of the influential research undertaken in the field of curriculum studies to compare the discussions in other educational fields with those in contemporary HE research and policy. We are particularly interested in the curriculum "crisis"_identified by Young (2013), as well as his characterisation of contemporary curriculum trends. For example, referring to Young's 
original writings, Priestley (2011) identifies three notable and interrelated trends or features of contemporary curriculum policy, as follows: the introduction and growing importance of national qualifications' frameworks, the shift or return to the emphasis on learning outcomes, and the move from the disciplinary subject-based approach to a more generic curriculum. Although Priestley positions these trends more as general educational challenges rather than specific to curriculum studies, the list is particularly topical and important in HE. Priestley (2011, p. 222) argues that "at a time when there has been an apparent decline in the application of curriculum theory to the emergence of new forms of curriculum in some areas, robust theory is badly needed to critique and address issues arising from the new curricula." Additionally, he points out that because of the widely discussed decline of curriculum theories, new curricula are often theoretically agnostic or build on theoretical contradictions, which have a further negative influence on curricular practices.

The most salient point about the perceived crisis in curriculum theories is articulated by Young (2013), who summarises that in the shift from instruction-related interests to ideology critiques, curriculum theories have lost their primary object - what is learned and how it is learned. One of the most topical and interesting curriculum debates across the whole educational sector precisely relates to the importance of the role and the position of curriculum theories in the actual developmental processes of education (see Young, 2014). In other words, given this lack of coherence, how can we realise the potential for theoretical approaches and research findings to be heard in education policy-making arenas and institutional strategies? This question and the division steer our perspective towards examining the role of curriculum theories in HE.

The HE scholars undertaking curriculum research have done so with a variety of approaches and methodologies, leading to a somewhat incoherent field of study (Annala et al., 2016). Indeed, it is questionable whether curriculum research in $\mathrm{HE}$ is an identifiable field, as it certainly is in the general education sector. Therefore, to contribute to prospective research on HE curriculum, it is important to have a general view of different curriculum theory approaches, the methods typically used and their relations to specific features of the HE field.

We argue that the dispute and the separation among different kinds of curriculum theoretical approaches are particularly important to overcome in the HE context. First, HE is experiencing an ongoing transformation in which the curriculum is increasingly becoming an essential aspect of strategic planning, especially in the competitive HE marketplace (Blackmore \& Kandiko, 2012). This situation marks a shift from the historical role of viewing the curriculum as basically the mechanism for transmitting knowledge between generations. Second, in universities, these strategic curriculum plans and decisions concerning implementation are usually made by people who lack an educational degree or background in the educational sciences. Instead, they often bring a breadth of experience in educational practices based on their earlier careers as teachers and researchers. However, their past experience may have overemphasised the technical or the practical role of the curriculum, determining the outcomes, the content and the best practices used 
in each institution. In turn, this matter is connected to what has been considered curriculum theories and their role in curriculum development work. Third, it is vital to understand the role of curriculum theory as part of the transnational political agenda and its steering mechanisms. Both critical and normative roles of curriculum theories are needed, for example, in examining the social impacts of competency-based and outcome-focused ideologies (see, e.g., Muller \& Young, 2014). According to Muller and Young (2014), learning theorists and curriculum and qualification designers have played major roles in these processes. There has been a drive to introduce national outcome-based qualification frameworks at all levels, including HE. Moreover, competence-based curriculum seems to be a norm and a fixed starting point in curriculum reform.

\section{Critical realist perspective on curriculum theories}

We have adopted a critical realist approach to this investigation of curriculum theories. Critical realism has become increasingly popular in recent curriculum-related studies (e.g., Priestley, 2011; Scott, 2010; Wheelahan, 2010). Common to these approaches is the assumption that critical realism, along with empiricism or pragmatism, is a meta-theory that affects how the curriculum is understood as a phenomenon. In contrast to other meta-theories, critical realism has a few important distinctions that make it a particularly useful starting point in examining theoretical approaches in curriculum studies (Scott, 2005). A detailed analysis of the foundations of critical realism is beyond the scope of this article, but in this brief overview, we introduce a few basic ontological starting points that have guided our analysis.

Though critical realists usually agree that an entity can exist independently of human knowledge, they perceive that there is no unmediated access to the world. The statement that our access is mediated means that whenever we reflect on something, we always use a pre-existing set of conceptual resources to understand it. This set can be individual (including beliefs and opinions), social or inter-subjective, guided by accepted theories, perspectives or social norms (Fleetwood, 2005). It follows that we are always one step behind the evolving and emergent nature of the social world and that "there is no outsider perspective that allows the individual access to complete knowledge, including knowledge of how the world works” (Scott, 2005, p. 636). Scott (2005) concludes that if we accept this idea of fallibilism, researchers cannot avoid a critical relationship, not only with previous and current understanding of phenomena but also with their own ways to describe these. Because of the openness, complexity and ambiguity of phenomena in the social world, these cannot be isolated and examined in a controlled environment. For this reason, we need to rely on careful conceptualisation and for our subject of study, try to abstract its components, tendencies, liabilities and their relations. Only after this step is it possible to construct empirical research settings or reduce the phenomena to personal experiences and meanings (Sayer, 2000). 
This idea of fallibilism leads to the assumption that an ontological theory presupposes an epistemological theory. This is important in researching curriculum theories in this chapter in the following ways. First, it justifies the significance and the meaning of our conceptual analysis, whose aim is to understand how theoretical approaches in HE curriculum research have been formulated. Following the general core ideas of critical realism helps us interpret the role (or lack thereof) of knowledge in curricular orientations and understand the meaning of different conceptions of learning within these orientations. Second, critical realism provides us with a theoretical frame to analyse the ontological, epistemological and methodological connections in curriculum theory orientations (e.g., Brown, 2009). It appears that studies focusing on particular curriculum approaches or practices have used certain methodologies and logics of knowledge creation to formulate or justify the theoretical frameworks that have been employed. This process of justification and argumentation has many layers, components and tendencies that relate to ontological and epistemological debates among research traditions of education (Brown, 2009; Pring, 2000), relations between HE and policy, and the role and the place of theoretical curriculum research in general. Perhaps most importantly, critical realism enables an articulation of how entwined theory, experience and knowledge are, all of which are variously promoted or underpromoted in different types of curricula.

\section{Shaping of curriculum theories and higher education}

How do we understand curriculum theories in HE research? Undertaking a basic search of the term 'curriculum theory' produces an array of articles and books published mainly in the 1970s-1990s, with critical discussions on the national curricula for schools, the testing culture, standardisations, accountability, political control and conflicting interests (e.g., Apple, 1986; Grundy, 1987; Kelly, 1977/2009; Pinar, Reynolds, Slattery, \& Taubman, 1995; Stenhouse, 1975). Although the context of curriculum studies often reflects some special national, often US-centric schooling problems, the questions and the tensions in developing a curriculum theory can be set against the discussions on the curriculum in HE, too. For this reason, we start by elaborating on the nature of curriculum theories.

First, curriculum theories are often confused with curriculum models (Vallance, 1982). For example, Kelly's book (1977/2009) is described as covering a "well-established curriculum theory" (e.g., Priestley \& Humes, 2010, p. 346) but is simultaneously regarded as presenting "three widely known curriculum planning models”, as follows: 1) the curriculum as content and education as transmission, 2) the curriculum as a product and education as instrumental and 3) the curriculum as a process and education as development. As such, the boundaries between a model and a theory are blurred, which may reflect the need for normative guidelines. This is topical in curriculum reforms that usually follow a model (e.g., competence-based training, problem-based learning). The models are often mediated through a language of progressivism, entailing a 
'learnification' language with a loose connection to theories but a more visible connection to practices and policies of education (Biesta, 2015; Wheelahan, 2009). This language may prove problematic if the fundamental premises and theories behind the models are not elaborated.

In 1982, the Theory into Practice journal published a special issue on the curriculum theory, which included some attempts to develop such a theory. In those articles, the question of whether there exists a single curriculum theory or many was problematised (Walker, 1982). Notably, in the field of curriculum studies, the curriculum theory is usually described in the singular form. Pinar (2008) defines it as "the interdisciplinary study of educational experience", emphasising it as a distinct field of study "with a unique history, complex present, an uncertain future" (p. 2). He continues that it is not a subfield of a single academic discipline, such as educational psychology or sociology of education, but is strongly influenced by the humanities and the arts. Although social sciences and psychology "have colonized much of the field of education", the curriculum theory rests on and owes its loyalty to the discipline and experience of education (p. 2).

However, the curriculum theory is not unified but consists of different, conflicting forms and approaches. Curriculum studies are broader than the curriculum theory, but some scholars identify themselves as belonging to the field of sociology of education instead of the broader domain of education or curriculum studies (Young, 2015). It is also noteworthy that curriculum theories may have overly narrow Anglophone, North European or Global South perspectives, as well as various disciplinary roots, such as philosophy and psychology (Deng, 2015; Lundgren, 2015). For example, HE researchers in North European countries often refer to the same educational and philosophical curriculum theories as those used in the research on compulsory education. Nonetheless, the theoretical thinking most often used by the UK, South African and Australian curriculum researchers is derived from Basil Bernstein's theory of curriculum and pedagogic practice, originating from the sociology of education (Annala et al., 2016).

We will draw from Bernstein's (2000) theories in more detail, but briefly, his conceptualisations of classification and framing within curricula have been influential on subsequent curricula. Bernstein's thinking originated from his research on social class in compulsory schooling, through which he developed the idea of "codes". Contrasting these codes as either "restricted" or "elaborated" signified whether students could understand and operate within the underlying assumptions permeating the school culture and curriculum. This work was controversial, given that it positioned working class students within a deficit model in relation to school success, but it led to Bernstein's interest in "school knowledge" and how knowledge was made legitimate within the curriculum through processes of selection and recontextualisation, as well as classification and framing. Classification simply refers to the strength of the boundaries around certain forms of knowledge. For example, a subject such as mathematics is strongly bounded, whereas a softer subject such as sociology is weakly bounded and shades into other subject areas, such as 
philosophy and psychology, quite easily. The strength of the boundaries makes certain subjects more exclusive and harder to access than others and are therefore usually of a higher status.

Given Bernstein's concerns about access to certain forms of knowledge, his theories have unsurprisingly been popular with scholars who take a critical approach to the HE curriculum. For instance, Coate (2006) employs a Bernsteinian framework to examine how women's studies as a new subject area in HE has gradually lost its legitimacy in the UK's HE context. Considering Bernstein's suggestion that subject areas that gain legitimacy in a curriculum help determine what is possible to think and who can think it, the selection and the recontextualisation of certain forms of knowledge, particularly in the HE context, are powerful shapers of society. However, within all the variations in curriculum theories, normative or critical approaches may be identified. We examine these particular approaches more closely in the next section.

\section{Nature of normative curriculum theories}

Despite the strong critical tradition described in the preceding section, curriculum theories play a normative role, too. These are expected to provide guidelines for curriculum design and practice, with certain norms to justify curriculum decisions. It does not mean defining the exact procedures for what is determined to be appropriate and what is not. Rather, it entails providing the frameworks and the guidelines for understanding the connection between theory and practice, along with the mechanisms and the powers behind curriculum decisions. Additionally, the normative role of curriculum theories reminds us of the important fact that the education system reproduces values in defining a 'good person' and a 'good society'; therefore, this normative role exerts a powerful influence on society (Young, 2014).

Curriculum theories have developed as acts following or counteractions against certain trends in society and education in general. They have also been used for their impacts on society and people. The grand narrative of normative curriculum theories often starts from the beginning of the 20th century, when John Franklin Bobbit (1918/1972) applied Taylor's scientific management in factory production to systems of educational management and planning. His idea was that a curriculum was a way to respond to the challenges of contemporary society and acquiesce to the demands of efficiency. Referring to Callaghan's book entitled Education and the Cult of Efficiency, Young (2013, p. 104) mentions Bobbit's confidence that the lessons from manufacturing could be successfully applied to schools: "The goal of schools-in other words 'what was to be learned' - was taken for granted, so the curriculum was interpreted as the instruction and efficient organization of teaching resources."

Based on Bobbit's theoretical ideas, Tyler (1949) introduces four principles for curriculum design, as follows: 1) defining learning objectives, 2) introducing useful learning experiences, 3) 
organising experiences to maximise their effects and 4) evaluating the process and revising the ineffective areas. Tyler's rationale may have wielded the most influence on worldwide curriculum design and practice; his principles can be found in curricula from primary to tertiary-level education. ${ }^{1}$ In HE, John Biggs' widely used model of constructive alignment relies on Tyler's principles (Biggs \& Tang, 2007). Constructive alignment has been criticised for being an outcomedriven, overly prescriptive model of curriculum development. However, Biggs (2016) denies that the model only serves a managerial agenda even if it has been used in this way. Although a prime example of outcome-based education, it is one of the most commonly promoted frameworks for improving teaching and learning (e.g., Hussey \& Smith, 2003).

Bobbit's idea of the curriculum as a means to respond to the challenges of contemporary society and acquiesce to the demands of efficiency is not far from the European Union's (EU's) contemporary initiatives to make HE more productive and effective in order to serve Europe's economy. The EU's HE modernisation agenda argues that "curricula are often slow to respond to changing needs in the wider economy" (European Commission, 2011, p. 12). "Involving employers and labour market institutions in the design and delivery of programmes, supporting staff exchanges and including practical experience in courses can help attune curricula to current and emerging labour market needs and foster employability and entrepreneurship” (pp. 12-13). These normative statements, which filter from the EU to national HE policy and practice, are new in $\mathrm{HE}$ for those subjects that traditionally enjoyed a large degree of autonomy in curriculum design, teaching and conducting research on issues relevant to scholarly communities. What has followed from the policy guidelines is that in curriculum thinking, the focus is shifting from broad knowledge structures to demonstrable and assessable packages of learning outcomes, competencies and abilities (e.g., Lundgren, 2015; Wheelahan, 2007).

When following outcome-based or competency-based curriculum thinking, methodological choices emphasise identifying and mapping the core norms (i.e., competencies and skills needed in working life). In these studies, the methodology may be a survey (Hurlimann, 2009), the Delphi Technique (Edgren, 2006), action research (Junyent \& Celi de Ciurana, 2008) or an interview (Bolander, Josephson, Marin, \& Lonka, 2006), among others. Documentary analyses have been undertaken as well to standardise curricula across institutions (e.g.,Wijetunge, 2009). These trends reflect the enterprises to develop and implement qualification frameworks. Comparative studies have also been conducted, with the aim of ascertaining whether a certain curriculum model is more effective than another (e.g., Peeraer et al., 2009). From the critical realist perspective, there seems to be a straightforward connection between the used methodological approaches and curriculum viewpoints. As Brown (2009) argues, curriculum choices are often underpinned by either

\footnotetext{
${ }^{1}$ A comprehensive description of Bobbit's and Tyler's ideas can be found, for example, in The Curriculum Studies Reader (Flinders \& Thornton, 2004).
} 
objectivist or constructivist conceptions of knowledge and learning. Different research approaches also reflect the ontological and the epistemological bases of curriculum theories. This connection can be problematic in two ways. First, it promotes the idea that the curriculum theory approach is somehow subordinate to the pedagogical approach or the learning theory or that the curriculum theory may be induced by those (Apple, 2004). Second, a selected methodological setting with its meta-theoretical assumptions on teaching and learning, along with the argumentation drawn from these, may end up in conflict with the ontological and the epistemological bases of curriculum thinking. It follows that curriculum theory viewpoints may be perceived as overly complicated, confusing and thus unnecessary. In this sense, it sounds more appealing to focus more on practical curriculum development (see Paraskeva, 2011, pp. 73-75; Young, 2014). As Paraskeva (2011) points out, this underrating of the theoretical aspect of the curriculum is also part of Tyler's legacy.

At times, we have observed a lack of systematic theoretical or methodological positioning behind the normative curriculum thinking; the governing experts, institutions or industries in certain disciplinary fields play a key role in defining what should be included in the curriculum (e.g., Craddock, O’Halloran, McPherson, Hean, \& Hammick, 2013). Young (2014) concludes that for some reason, education specialists who base the curriculum development on the prescription type of changes seem to think that no one would actually disagree with their ideas. "The assumptions underpinning such curriculum models are not seen as needing evidence or arguments to support them” (p. 195). A more recent study (Annala et al., 2016) finds that besides the official authorities, different interest groups tend to embed relevant competencies, such as entrepreneurship, into the curriculum (Penaluna \& Penaluna, 2009), along with other ideas based on social or human ends, including internationalisation (e.g., Clifford, 2009), sustainability (e.g., Junyent \& Celi de Ciurana, 2008) and inclusion (e.g., Chapman, 2007/2008). All these developments reflect the social worlds around universities and raise the question of whether the university curriculum can be an isolated entity or should take a stand on issues that are not directly related to the disciplinary content of a curriculum.

The outcome-based or the competency-based curriculum thinking strongly relies on the premises of normative curriculum theories. Wheelahan (2009) states that although the competency-based curriculum emphasises student-centred language, learning as a negotiated activity and freedom of choice (of both students and teachers) are controlled by tightly defined learning outcomes and their assessment criteria. The competency-based curriculum thinking may genuinely depend on the student-centred approach to learning and contribute to the understanding of what university studies are about and what students are expected to achieve during their studies and through it, reflect the quality standards of the programme in question. Nonetheless, the normative, applied-science curriculum approaches have received a fair amount of critique from curriculum researchers. The criticism focuses on the narrow, mechanical, individualistic and end product-like view of education, reflecting behaviouristic conceptions of learning (e.g., Anwaruddin, 2016). It is perceived to promote and serve mainly the utilitarian interests of society (e.g., McKernan, 2008; 
Stenhouse, 1975). McKernan (2008) argues for a curriculum theory that rejects the use of educational objectives determined in advance. The desire for more open-ended, creative and serendipitous learning opportunities is the driver behind some critical curriculum approaches, which we explore more closely in the next section.

\section{Critical curriculum theories}

Critical curriculum theories comprise a wide-ranging and overlapping field. Marsh (2009) locates the beginning of the critical-explanatory branch of research to the 1970s. Arising from the criticism against Tyler's rationale, the idea of the curriculum as a process was introduced. Stenhouse's (1975) process model of the curriculum emphasised the student's subjectivity and potential for growth, based on flexible and open-ended direction, dialogue and democratic values, as well as Pinar's autobiographical curriculum (e.g., 2014). In 1979, Pinar founded The Journal of Curriculum Theorizing, which provided new perspectives following psychoanalytical and phenomenological traditions, for example. These traditions developed towards what is currently known as the Anglo-American curriculum studies tradition. Of course, it is quite diverse itself; for example, Pinar's highly influential production with Deweyan and psychoanalytical origins has many unique features that are not shared by the works of other great figures, such as Michael Apple and Tom Popkewitz, building their critiques on neo-Marxist foundations (Young, 2014).

Some particularly interesting roots of the HE critical curriculum theory can be traced back to the Bildung-Didaktik tradition. It was born within the European social theory that focused on the education of all people (allgemeine Bildung). Being the main societal idea of the nation state, Bildung was influenced not only by the Enlightenment but also by scientific empiricism and instrumentalism. Individuality is a vital concept in Bildung. It refers to a spiritual-intellectual possibility that can be cultivated through education. As such, it differs from the competitive individualism of "liberal economics and politics" (Luft, 2003, as cited in Pinar, 2011, p. 3). In other words, Bildung is based on the idea that we grow up as humans and individuals because of the possibilities provided by culture. As a view of education, Bildung highlights that only an individual who is extensively civilised and has had diverse opportunities for self-development understands the interconnection with others and wants to pursue public good. This sense of communality is the ethical basis for the individual's actions.

The concept of Bildung was essential in considering the ideas of European universities and included the notion of strong autonomy and independence from society even though the fundamental idea was to educate good citizens. As such, it was an opening and the intellectual basis for critical curriculum theory approaches in HE. The German philosopher Wilhelm von Humboldt took allgemeine Bildung as the cornerstone of his thinking and developed it further in the context of different levels of education (Konrad, 2012). Despite a lot of debate on the actual 
importance of Humboldt's writings (see, e.g., Scott \& Pasqualoni, 2016), his idea of a university was exported worldwide, becoming a highly influential and popular reflection point for HE institutions. As Rohstock (2012, p. 178) puts it, with Humboldt's conception of a university, "it became possible to defend a global intellectual culture of self-determination, which remains to this day an essential component of self-identity in broad circles of academia.” Along with the history of HE, the Humboldtian idea has been reinvented over and over to oppose different kinds of threats to academic freedom. When political steering mechanisms try to have an impact on the HE curriculum, the university's primary task of promoting Bildung is often put to the fore.

The Bildung-Didaktik tradition and the idea of the curriculum as a process are not often conceptually visible in HE curriculum research, but similar features can be found from other critical approaches. For example, Barnett and Coate (2006) have introduced the curriculum as engagement, exploring how students' personal relationship with knowledge intertwines with their changing sense of being, as an overlooked but important feature in the HE curriculum. Later, feminist and post-colonial theorists, such as Melanie Walker and Madeliene Grumet, have also followed the critical curriculum studies approach by emphasising issues of social justice, the development of human capabilities and other emancipatory goals (e.g., Walker \& Unterhalter, 2007). Much of the interest in social justice in this work is theoretical; for instance, the human capability approaches that inform Walker and Unterhalter's (2007) study are philosophical in nature. These theories are based on strong ideological beliefs in the role that HE can play in ensuring individuals' capability to make valuable contributions to society. Methodologically, the critical approaches concentrate on the philosophical or the sociological analysis of power relations around curriculum thinking even though the studies may also obtain empirical data, such as through case studies (e.g., Fahey, 2012) or interviews (e.g., Garraway, 2010).

According to Marsh (2009), all critical-explanatory curriculum theories and their proponents share their concern about the relationship between society or culture and education. He points out (as alluded to above) that influential writers such as Michael Young and Basil Bernstein were sociologists who focused on power and social control. Popular topics of critical curriculum research have thus comprised the role of education and the curriculum in oppressing groups disadvantaged by class, race and gender. Common to this approach is their interest in "the knowledge of the powerful". Another line of critical studies has focused on "powerful knowledge" and how knowledge as the foundation of schooling and the curriculum has lost its primary place and function. Both of these play an important part in understanding the role of curriculum research in HE (Young, 2014).

Bernstein's (2000) work illuminates how curricula construct powerful knowledge that filters and therefore excludes the "unthinkable" and the "yet-to-be-thought". Bernstein is not interested in the normative conception of learning outcomes but produces insights into how the gatekeeping functions of powerful knowledge in the curriculum can exclude certain groups from acquiring 
knowledge. He distinguishes powerful knowledge - also called conceptual, abstract and esoteric knowledge - from everyday, contextual and mundane knowledge (Bernstein, 2000; Wheelahan, 2007). As mentioned, these types of questions about who is in a position to make curriculum choices and has access to powerful forms of knowledge have been extensively developed in curriculum research in HE (e.g., Clegg, 2011; Shay, 2013).

However, the translation of these philosophical goals into curriculum research, and eventually curriculum change, is not straightforward. What has been observed in Western HE in recent years has been a re-examination of the role that the HE curriculum can play in terms of enabling students to meet the challenges of 21st-century life. This focus has partly been driven by the HE sector's general interest in the characteristics of the undergraduate curriculum. As Quinlan (2016, p. 1042) states, "Many research universities around the world are revising or reconsidering their curricula, with a view towards interdisciplinarity and considerations of coherence, breadth, depth, community engagement and globalisation” (see also Blackmore \& Kandiko, 2012). As a result, many universities now shape their curricula through identified graduate attributes, such as critical thinking, lifelong learning and social responsibility.

Some of these approaches to curriculum change are aligned with the issues of social justice and ethics. Others are much more instrumental and designed to equip students for employability. The key point here (as mentioned) is that most of the strategic curriculum changes are being driven by non-educationalists and in the absence of a strong curricular theory shaping these changes. It is thus not surprising that institutions can end up with curriculum strategies full of tensions and contradictions. We return to this point in the concluding section.

\section{Debates on curriculum theories and research methods in terms of practice and policy}

Young (2014) points out that a main reason for the division between critically oriented theories and more practical or normative ones involves the disagreement about the object and the limits of curriculum theories. This matter has led to a situation where researchers look for "critical concepts in philosophy, politics, and literary theory even though they have never engaged with any educational issues, let alone curricula” (p. 196). This seems to be particularly the case in the complex relation between critical perspectives and the HE curriculum, although it is understandable that philosophical and political theorisations are sometimes vital for examining the interconnectedness of social mechanisms, identity and educational structures. However, Young's idea is to show that understanding the curriculum as an educational concept is the basis for defining the object of the curriculum theory, too. He states that this object is the curriculum knowledge specialised knowledge organised for the use of formal education - which the curriculum theory should be able to analyse and critique. 
Young (2013, p. 103) suggests that the crisis in the curriculum theory is due to an ongoing process where "access to knowledge" has been largely neglected from the theory. His critique targets curriculum theorists' recent reluctance to "address epistemological issues concerning questions of the truth, and reliability of different forms of knowledge and how such issues have both philosophical and sociological dimensions” (p. 103). The result of all this is that current debates about knowledge and the curriculum have slipped away from the hands of educationalists to those of politicians and government officials (Young, 2013).

On the other hand, critical curriculum theories and research have been perceived as "selfjustifying” without the need to address the issues of normative practices (Young, 2014, p. 195). This issue poses the danger of avoiding the fact that education is by nature a practical activity and that to understand the curriculum, we need to comprehend the role of educational knowledge within those specialised practices. The object of action in curriculum practice may often be lost because of the disinterest in curriculum theories by practitioners and people responsible for academic reforms. Young (2014) argues that from the normative perspective, critical theories seem unappealing because they challenge all the basic assumptions without providing alternatives. Moreover, there seems to be some space and demand for pragmatically oriented curriculum research without a particularly strong epistemological or ontological basis.

In studies concerning developmental processes and reforms, surprisingly often, the key concept (curriculum) is not defined and lacks a theoretical framework (Annala et al., 2016; Coate, 2009). If the idea behind curriculum thinking is unclear for those responsible for the development of teaching and learning in HE institutions, it leads to contradictions among participants with a different understanding of the object of the activity. Both normative and critical theory approaches also vary in their relation to research methodology and in how they use research and data in their argumentation. From a broader perspective, the relation between methodological choices and theoretical conceptions of the HE curriculum has been essential in the process where curriculum practices have been justified. The gap across the curriculum's theoretical, methodological and practical worlds may be a contributing factor for the lack of an identifiable status of curriculum studies in the field of HE research.

\section{Rethinking the divide between normative and critical curriculum theories}

If we are at a critical juncture in terms of needing a more coherent understanding of the role and the nature of HE curricula, how do we bring together the normative curriculum theories with those that take a critical approach? Indeed, the previous discussion and those echoed elsewhere suggest that curriculum theory is in a crisis (e.g., Baker, 2015; Deng, 2015; Hoadley, 2015; Lundgren, 2015; McEneaney, 2015; Wheelahan, 2015; Young, 2015). Many scholars have stated that curriculum theory has declined in both status and practice by focusing mainly on an ideologically 
based critique (Priestley \& Humes, 2010; Wheelahan, 2010). By doing so, curriculum theories have lost sight of their primary object - what is taught and learned - and how existing theories could contribute to practices in various contexts, including HE (cf. Priestley, 2011; Young, 2013). Most of the researchers cited in this chapter have tended to rely more on sociological than on educational theories, and this orientation has surely shaped the debates in particular ways. Although from the early days, the key question in curriculum studies has been "what knowledge is of most worth" (Pinar, 2011, p. xvi), we have suggested that Bernstein has been the authority on the curriculum in the HE context.

The question here is whether Bernstein's work, whilst on a meta level is concerned with issues of social justice and therefore aligned with the critical tradition, could also offer a bridge between normative and critical approaches. His detailed elaborations of the ways in which knowledge is selected, recontextualised and presented in curricula offer insights into the relationships between everyday and abstract knowledge. He suggests that the separation of everyday knowledge from abstract knowledge can result in an inability to translate everyday knowledge into making sense of new contexts.

His theories have therefore prompted HE curriculum researchers to pay attention to knowledge, which is what Young (e.g., 2014) suggests has been lacking in curriculum studies on compulsory schooling. Particularly, explorations of students' access to and relationship with disciplinary knowledge through the works of Ashwin, Abbas, and McLean (2014) and Shay (2013), among others, help illuminate the role that knowledge (as presented through the curriculum) plays in excluding or enabling access and progression. Bernstein has essentially enabled HE researchers to undertake a fairly detailed forensic exploration of students' encounters and entanglements with knowledge, whilst maintaining the focus on the importance of classifying and framing that knowledge in shaping such encounters.

Barnett and Coate (200드) also draw from Bernsteinian thinking to develop a schema that enables examining the relationship and the level of overlap among the knowledge, action and being domains (or those of knowing, acting and becoming) in any curriculum. The relationship between the students' sense of self and encounters with disciplinary knowledge is again the main focus but from the viewpoint of the curriculum designers. Barnett and Coate (2005) suggest the necessity for those who engage in the process of selecting and recontextualising knowledge in the curriculum to think about the potential implications for the students' own sense of their developing identities as they journey through the curriculum. According to Barnett and Coate, at present, the students' sense of self or being in the world is often an implicit aspect of curricular design. Many of the academics they interviewed focused on disciplinary knowledge or the product rather than the process, as Fraser and Bosanquet (2006) also suggest. The academics' emphasis on knowledge and content could help explain some of the exclusionary processes found by the researchers (mentioned above) who explore the student perspective. The academics who design curricula could 
pay much less attention to the student experience and the processes of learning disciplinary knowledge than should perhaps be warranted.

To summarise in simpler terms, we suggest that without understanding the basic meanings of curriculum theories, it has been easier for curriculum developers to lose sight of the interrelationship between knowledge and students' sense of self. The normative theorists have disregarded knowledge as their focus has turned increasingly to outcomes. The critical theorists have followed the social implications of knowledge selection alongside a critique of outcomes, without offering a clearly articulated formulation of the nature of a critical and outcome-based approach. Perhaps more dangerously, we have witnessed an expansion of curriculum decision making that is far removed from curriculum theorists with a deep comprehension of its role, as well as from academics who design curricula at a local level and tend to have a partial understanding of its role.

\section{References}

Annala, J., Lindén, J., \& Mäkinen, M. (2016). Curriculum in higher education research. In J. Case \& J. Huisman (Eds.), Researching higher education. International perspectives on theory, policy and practice (pp. 171-189). London: Society for Research into Higher Education \& Routledge.

Anwaruddin, S. (2016). Contesting the violence of Tylerism: Towards a cosmopolitan approach to the curriculum of second language teaching. Teaching in Higher Education, 21(4), 429-441.

Apple, M. (1986). Controlling the work of teachers. In D. J. Flinders \& S. J. Thornton (Eds.), The curriculum studies reader. New York: Routledge Falmer. Reprinted. Originally Chapter 2 in Teachers and texts, New York: Routledge \& Kegan Paul.

Apple, M. (2004). Ideology and curriculum (3rd ed.). New York: Routledge Falmer.

Ashwin, P., Abbas, A., \& McLean, M. (2014). How do students' accounts of sociology change over the course of their degrees? Higher Education, 67(2), 219-234.

Baker, D. P. (2015). A note on knowledge in the schooled society: Towards an end to the crisis in curriculum theory. Journal of Curriculum Studies, 47, 763-772.

Barnett, R., \& Coate, K. (2005). Engaging the curriculum in higher education. First published 2005. London: Society of Research into Higher Education \& Open University Press.

Bernstein, B. (2000). Pedagogy, symbolic control and identity. Oxford: Rowman and Littlefield. 
Biesta, G. (2015) What is education for? On good education, teacher judgement, and educational professionalism. European Journal of Education, 50(1), 75-87. http://dx.doi.org/10.1111/ejed.12109

Biggs, J. (2016). Constructive alignment [Personal web page]. Retrieved from http://www.johnbiggs.com.au/academic/constructive-alignment/

Biggs, J., \& Tang, C. (2007). Teaching for quality learning at university: What the student does. (3rd ed.). London: Society for Research into Higher Education \& Open University Press.

Blackmore, P., \& Kandiko, C. (2012). Strategic curriculum change: Global trends in universities. Abingdon: Routledge.

Bobbit, J. (1918/1972). The curriculum. New York: Arno Press.

Bolander, K., Josephson, A., Mann, S., \& Lonka, K. (2006). Teachers promoting expertise in medical education: Understanding the role of the core curriculum. Quality in Higher Education, 12(1), 41-55.

Brown, G. (2009). The ontological turn in education. Journal of Critical Realism, 8(1), 5-34. http://dx.doi.org/10.1558/jocr.v8i1.5

Chapman, V. (2007/2008). Developing inclusive curricula. Learning and Teaching in Higher Education, 3, 62-89.

Clegg, S. (2011). Cultural capital and agency: Connecting critique and curriculum in higher education. British Journal of Sociology of Education, 32(1), 93-108.

Clifford, V. A. (2009). Engaging the disciplines in internationalising the curriculum. International Journal for Academic Development, 14(2), 133-143.

Coate, K. (2006). Imagining women in the curriculum: The transgressive impossibility of women's studies. Studies in Higher Education, 31(4), 407-421.

Coate, K. (2009). The curriculum. In M. Tight, K. H. Mok, J. Huisman, \& C. Morphew (Eds.), The Routledge international handbook of higher education. London: Routledge.

Craddock, D., O’Halloran, C., McPherson, K., Hean, S., \& Hammick, M. (2013). A top-down approach impedes the use of theory? Interprofessional educational leaders' approaches to 
curriculum development and the use of learning theory. Journal of Interprofessional Care, 27, 6572.

Deng, Z. (2015). Content, Joseph Schwab and German Didaktik. Journal of Curriculum Studies, 47, 773-786.

Edgren, G. (2006). Developing a competence-based core curriculum in biomedical laboratory science: A Delphi study. Medical Teacher, 28(5), 409-417.

European Commission. (2011). Supporting growth and jobs: An agenda for the modernisation of Europe's higher education systems. Luxembourg: Publications Office of the European Union. http://eur-lex.europa.eu/legal-content/en/ALL/?uri=CELEX:52011DC0567

Fahey, S. J. (2012). Curriculum change and climate change: Inside outside pressures in higher education. Journal of Curriculum Studies, 44(5), 703-722.

Fleetwood, S. (2005). Ontology in organization and management studies: A critical realist perspective. Organization, 12(2), 197-222.

"http:/dx.doi.org/10.1177/1350508405051188"

Flinders, D. J., \& Thornton, S. J. (Eds.). (2004). The curriculum studies reader (2nd ed.). New York: Routledge Falmer.

Fraser, S. P., \& Bosanquet, A. M. (2006). The curriculum? That's just a unit outline, isn't it? Studies in Higher Education, 31(3), 269-284.

Garraway, J. (2010). Knowledge boundaries and boundary-crossing in the design of workresponsive university curricula. Teaching in Higher Education, 15(2), 211-222.

Grundy, S. (1987). Curriculum: Product or praxis. Lewes: Falmer.

Hoadley, U. (2015). Michael Young and the curriculum field in South Africa. Journal of Curriculum Studies, 47, 7ㅍ3-749.

Hurlimann, A. C. (2009). Responding to environmental challenges: An initial assessment of HE curricula needs by Australian planning professionals. Environmental Education Research, 15(6), 643-659.

Hussey, T., \& Smith, P. (2003). The uses of learning outcomes. Teaching in Higher Education, 8(3), 357-368. 
Junyent, M., \& Celi de Ciurana, A. M. (2008). Education for sustainability in university studies: A model for reorienting the curriculum. British Education Research Journal, 34(6), 763-782.

Kelly, A. V. (1977/2009). The curriculum - theory and practice (6th ed.). London: Sage.

Konrad, F.-M. (2012). Wilhelm von Humboldt's contribution to a theory of Bildung. In P. Siljander, A. Kivelä, \& A. Sutinen (Eds.), Theories of Bildung and growth: Connections and controversies between continental educational thinking and American pragmatism (pp. 107-124). Rotterdam: Sense Publishers.

Lundgren, U. (2015). What's in a name? That which we call a crisis? Journal of Curriculum Studies, 47, 787-801.

Marsh, C. J. (2009). Key concepts for understanding curriculum (4th ed.). London: Routledge.

McEneaney, E. (2015). Finding knowledge on the Internet: Implications for the knowledge-driven curriculum. Journal of Curriculum Studies, 47, 802-819.

McKernan, J. (2008). Curriculum and imagination: Process theory, pedagogy and action research. London: Routledge. https://dx.doi.org/10.4324/9780203946930

Muller, J., \& Young, M. (2014). Disciplines, skills and the university. Higher Education, 67(2), 127-140. http://dx.doi.org/10.1007/s10734-013-9646-4

Paraskeva, J. M. (2011). Conflicts in curriculum theory: Challenging hegemonic epistemologies. New York: Palgrave Macmillan.

Peeraer, G., De Winter, B. Y., Muijtjens, A. M. M., Remmen, R., Bossaert, L., \& Scherpbier, A. J. J. A. (2009). Evaluating the effectiveness of curriculum change. Is there a difference between graduating student outcomes from two different curricula? Medical Teacher, 31, e64-e68.

Penaluna, A., \& Penaluna, K. (2009). Creativity in business/business in creativity. Transdisciplinary curricula as an enabling strategy in enterprise education. Industry and Higher Education, 23(3), 209-219.

Pinar, W. F. (2008). What is curriculum theory? Edition published in the Taylor \& Francis eLibrary. Originally published 2004. Mahwah, NJ: Lawrence Erlbaum.

Pinar, W. F. (2011). The character of curriculum studies. Bildung, currere and the recurring question of the subject. New York: Palgrave Macmillan. 
Pinar, W. F. (Ed.). (2014). International handbook of curriculum research (2nd ed.). New York: Routledge.

Pinar, W. F., Reynolds, W. M., Slattery, P., \& Taubman, P. M. (1995). Understanding curriculum. An introduction to the study of historical and contemporary curriculum discourses. New York: Peter Lang.

Priestley, M. (2011). Whatever happened to curriculum theory? Critical theory and curriculum change. Pedagogy, Culture and Society, 19(2), 221-237.

Priestley, M., \& Humes, W. (2010). The development of Scotland's curriculum for excellence. Amnesia and déjà vu. Oxford Review of Education, 36, 345-361.

http://dx.doi.org/10.1080/03054980903518951

Pring, R. (2000). The 'false dualism' of educational research. Journal of Philosophy of Education, 34(2), 247-260. http://dx.doi.org/10.1111/1467-9752.00171

Quinlan, K. M. (2016). Developing student character through disciplinary curriculum: An analysis of UK QAA subject benchmark statements. Studies in Higher Education, 41(6), 1041-1054.

Rohstock, A. (2012). Some things never change: The invention of Humboldt in western higher education systems. In P. Siljander, A. Kivelä, \& A. Sutinen (Eds.), Theories of Bildung and growth: Connections and controversies between continental educational thinking and American pragmatism (pp. 165-182). Rotterdam: Sense Publishers.

Sayer, A. (2000). Realism and social science. London: Sage.

Scott, D. (2005). Critical realism and empirical research methods in education. Journal of Philosophy of Education, 39(4), 633-646. http://dx.doi.org/10.1111/j.1467-9752.2005.00460

Scott, D. (2010). Education, epistemology and critical realism. London: Routledge.

Scott, A., \& Pasqualoni, P. P. (2016). Evoking Humboldt: Universities in the German-speaking world. In J. E. Cote \& A. Furlong (Eds.), Routledge handbook of the sociology of higher education (pp. 211-222). New York: Routledge.

Shay, S. (2013). Conceptualizing curriculum differentiation in higher education: A sociology of knowledge point of view. British Journal of Sociology of Education, 34(4), 563-582. 
Stenhouse, L. (1975). An introduction to curriculum research and development. London: Heinemann.

Tyler, R. (1949). Basic principles of curriculum and instruction. Chicago: University of Chicago Press.

Vallance, E. (1982). The practical uses of curriculum theory. Theory into Practice, 21(1), 4-10.

Walker, D. F. (1982). Curriculum theory is many things to many people. Theory into Practice, 21(1), 62-65.

Walker, M., \& Unterhalter, E. (2007). (Eds.). Amyarta Sen's capability approach and social justice in education. Basingstoke: Palgrave Macmillan.

Wheelahan, L. (2007). How competency-based training locks the working class out of powerful knowledge: A modified Bernsteinian analysis. British Journal of Sociology of Education, 28(5), 637-651. http://dx.doi.org/10.1080/01425690701505540

Wheelahan, L. (2009). The problem with CBT (and why constructivism makes things worse). Journal of Education and Work, 22(3), 227-242. http://dx.doi.org/10.1080/13639080902957913

Wheelahan, L. (2010). Why knowledge matters in curriculum. A social realist argument. London: Routledge.

Wheelahan, L. (2015). Not just skills: What a focus on knowledge means for vocational education. Journal of Curriculum Studies, 47, 750-762.

Wijetunge, P. (2009). A critical evaluation of the curriculum development strategy of the LIS education programs in Sri Lanka. Library Review, 58(9), 670-684.

Young, M. (2013). Overcoming the crisis in curriculum theory: A knowledge-based approach. Journal of Curriculum Studies, 45, 101-118.

Young, M. (2014). Curriculum theory: What is it and why is it important? Cadernos de Pesquisa, 44(151), 191-201. http://dx.doi.org/10.1590/198053142851

Young, M. (2015). Curriculum theory and the question of knowledge: A response to the six papers. Journal of Curriculum Studies, 47(6), 820-837.

http://dx.doi.org/10.1080/00220272.2015.1101493 